\title{
Adverse Event MedDRA Body System or Organ Class Code
}

National Cancer Institute

\section{Source}

National Cancer Institute. Adverse Event MedDRA Body System or Organ Class Code. NCI Thesaurus. Code C117377.

A coded value specifying the type of body system or organ class related to the adverse event from the Medical Dictionary for Regulatory Activities (MedDRA). 